\title{
A FUNÇÃO DO SERVILCOS ECOSSISTÊMICOS NA GESTÃO DOS RISCOS DE DESASTRES PELO DIREITO: CONEXÕES ENTRE A POLÍTICA NACIONAL DE PROTEÇÃO E DEFESA CIVIL E O ESTATUTO DA METRÓPOLE
}

\author{
THE FUNCTION OF ECOSYSTEM SERVICES IN RISK MANAGEMENT OF DISASTERS BY LAW: \\ CONNECTIONS BETWEEN NATIONAL POLICY AND CIVIL DEFENSE AND PROTECTION AND THE \\ METROPOLIS STATUTE
}

Kátia Ragnini Scherer ${ }^{1}$

\section{Resumo}

O artigo aborda a função dos serviços ecossistêmicos na gestão dos riscos de desastres pelo Direito, a partir de comunicação entre a Política Nacional e Proteção e Defesa Civil e o Estatuto da Metrópole. O objetivo é analisar reflexivamente o papel dos serviços ecossistêmicos na gestão dos riscos de desastres pelo Brasil por interconexões entre as Leis no.12.608/12 e no13.089/15. O método de abordagem é o da análise funcional, compreendido como um método comparativo em que sua introdução na realidade possui a função de olhar algo que já existe com outras possibilidades de observação (LUHMANN, 1990, p.72). O método de procedimento é o monográfico. Como resultado apresenta a possibilidade de que políticas públicas de proteção aos serviços ecossistêmicos integrem o Planos de Desenvolvimento Urbano Integrado com a função preventiva e/ou mitigatória de desastres, construindo metrópoles e aglomerados urbanos resilientes. Está estruturado em três partes: a primeira aborda os serviços ecossistêmicos e sua gestão pelo Direito, a segunda investiga políticas públicas de pagamento por serviços ecossistêmicos preventivos ou mitigatórios aos desastres no Brasil e a terceira analisa interconexões entre a Política Nacional de Proteção e Defesa Civil e o Estatuto da Metrópole trazendo os serviços ecossistêmicos como possibilidade comunicativa.

\section{Palavras-chave}

Desastres; serviços ecossistêmicos; Política Nacional de Proteção e Defesa Civil; Estatuto da Metrópole; Plano de Desenvolvimento Urbano Integrado.

\footnotetext{
1 Doutora em Direito pela Universidade do Rio dos Sinos-UNISINOS. Mestre em Ciência Jurídica pela Universidade do Vale do Itajaí - UNIVALI. Professora do Departamento de Direito da Universidade Regional de Blumenau - FURB. ORCID iD: http://orcid.org/0000-0002-9020-3623. Instituição: Universidade Regional de Blumenau - FURB, Santa Catarina. Brasil. E-mail: katiarscherer@gmail.com
} 


\section{Abstract}

The article addresses the role of ecosystem services in the management of disaster risk by law from the connections between the National Policy and Protection and Civil Defense and the Statute of the Metropolis. The objective is to reflect reflexively on the role of ecosystem services in disaster risk management in Brazil through interconnections between Laws no.12.608 / 12 and no. 1389/15. The method of approach is that of functional analysis, understood as a comparative method in which its introduction actually has the function of looking at something that already exists with other possibilities of observation (LUHMANN, 1990, p.72). The procedure method is monographic. As a result, it presents the possibility that public policies to protect ecosystem services integrate the Integrated Urban Development Plans with the preventive and / or disaster mitigation function, building resilient metropolis and urban agglomerations. It is structured in three parts: the first deals with ecosystem services and their management by law, the second investigates public policies for payment for preventive or mitigating ecosystem services in Brazil, and the third examines interconnections between the National Policy on Protection and Civil Defense and the Statute of the Metropolis bringing ecosystem services as a communicative possibility.

Keywords: Disasters; ecosystem services; National Protection and Civil Defense Policy; Statute of the Metropolis; Integrated Urban Development Plan.

\section{INTRODUÇÃO}

Todos os dias as notícias sobre o clima e desastres revelam a crescente complexidade da temática em diversos contextos sociais como a Ciência, a Economia, a Política e o Direito. Dados indicavam que no primeiro semestre de 2017 várias cidades pelo planeta já apresentam vulnerabilidades e a falta de estruturas resilientes para enfrentar ondas de calor fora de padrões que atingem a Inglaterra e França, incêndio florestal em Portugal, intensificação da seca na África e inundações no sul do Brasil (WAYCARBON, 2017). A mudança do clima a patamares considerados como "terreno desconhecido" (NASA, 2018) provocam a exigência de uma reflexão sobre a forma como as respostas podem ou não apresentar horizontes de estabilização, especialmente considerando um critério de territorialidade dos danos provocados por desastres ambientais/climáticos, ou seja, o território das cidades. Em recente série a NASA apresenta em imagens um paralelo do que ocorreu nas últimas décadas em termos de descongelamento de rios e mares, a intensificação de eventos climáticos extremos como furacões, deslizamentos e inundações, além de traços da ação humana, como a expansão das cidades, por exemplo (NASA.2018). 
O Intergovernmental Painel on Climat Change de 2018 (IPCC, 2018) faz um diagnóstico de intensificação, recorrência e severidade de eventos catastróficos relacionados à mudança do clima e os impactos sociais, econômicos, políticos e ambientais dos desastres, agravados especialmente quando o critério é o do território dos grandes aglomerados urbanos.

Neste contexto torna-se necessária e atual a reflexão da forma de gestão a ser assimilada para a redução desta nova complexidade pelo Direito. A priori, a terminologia "risco climático" vem sendo assimilada para nominar não só os eventos ambientais, mas aqueles decorrentes ou potencializados pelas mudanças climáticas (ANTUNES, 2012; CARVALHO, 2016; FARBER; 2016; SCHERER, 2017).

A função do Direito em relação ao Direito enquanto um conjunto de processos a serem operados por instituições jurídicas necessita assimilar seus fundamentos de prevenção e precaução e, em um recorte específico, surgem os serviços sistêmicos e sua função diferenciada voltada a evitar ou minimizar os impactos e danos decorrentes de desastres, cuja intensidade, volume e recorrência são associados às mudanças no clima.

No contexto jurídico nacional a Política Nacional de Proteção e Defesa Civil - Lei no 12.6608/2012- PNPDEC configura-se como um marco regulatório na gestão dos desastres e apresenta como diretriz a necessária integração com outras políticas públicas. Esta abertura legislativa dialoga reflexivamente com o Estatuto da Metrópole - Lei no 13.089/2015- que assimilou o Pagamento por Serviços Ecossistêmicos no Plano de Desenvolvimento Urbano Integrado da metrópoles e aglomerados urbanos, como superação da dogmática ambiental no que se refere à clássica divisão de competências federativas.

Portanto, a problemática que se apresenta no presente estudo é a de responder sob quais condições é possível analisar reflexivamente o papel dos serviços ecossistêmicos na gestão dos riscos de desastres no Brasil a partir da aplicabilidade conjunta dos instrumentos jurídicos da PNPDEC e do Estatuto da Metrópole.

Para tanto o objetivo cinge-se em analisar reflexivamente o papel dos serviços ecossistêmicos na gestão dos riscos de desastres no Brasil e a possível aplicabilidade conjunta dos instrumentos jurídicos da PNPDEC e do Estatuto da Metrópole.

O artigo está estruturado em três partes: a primeira aborda os serviços ecossistêmicos e sua gestão pelo Direito, a segunda investiga as Políticas Públicas de Pagamento por Serviços Ecossistêmicos e sua orientação a gestão de riscos de desastres no Brasil e, ao final, a terceira analisa a interconexões entre a Política Nacional de Proteção e Defesa Civil e o Estatuto da Metrópole, trazendo os serviços ecossistêmicos como possibilidade comunicativa. 


\section{SERVIÇOS ECOSSISTÊMICOS E SUA GESTÃO PELO DIREITO}

Os processos ecológicos prestam uma gama de serviços que beneficiam todos os organismos que vivem na terra e são responsáveis pela manutenção da vida no planeta. Além do valor intrínseco que possuem como bens ambientais, tais processos, apropriados a partir de seus benefícios diretos ou indiretos, denominam-se "serviços ecossistêmicos" e exercem, uma comunicação na relação do valor da diversidade e genética das espécies, da produção, transformação e manutenção da energia e da ciclagem de nutrientes-ciclos biogeoquímicos-(PEREIRA, WINCKLER, FRANCO, 2008, p. 144).

A terminologia "serviços ecossistêmicos" se construiu, contudo, a partir do sentido de assimilação mais restrito da contribuição que todos os bens, produtos e serviços derivados dos ecossistemas prestam para o bem-estar das populações humanas. Assim os serviços ecossistêmicos se constituem no conjunto de benefícios que o homem obtém dos ecossistemas (MEA, 2005).

Esta comunicação produzida pelos serviços ecossistêmicos em relação aos diversos subsistemas sociais intensificou-se a partir da segunda metade do século passado com a inclusão de temáticas como degradação ambiental, mudanças climáticas, poluição, escassez de alimentos, entre outras, sendo assimilados paulatinamente pelas agendas da Ciência, da Política, da Economia e do Direito.

Em termos de abrangência territorial, uma das respostas estabilizadoras foi a pesquisa realizada pelo MEA com o objetivo de avaliar, em nível mundial, as consequências das alterações dos ecossistemas e fixar bases científicas no sentido de orientar as decisões de otimização de sua conservação, uso e contribuição para o bem-estar humano. Tratou-se de um processo que requereu a construção de rede de informações multidisciplinares advindas preponderantemente da Ciência, da Política da Economia e do Direito (MEA, 2005, p. ii, vii-viii).

Em termos de policontexturalidade, ou seja, da assimilação de elementos que integram a Ciência, a Economia e a Política o desafio que se coloca para o Direito é o identificar e processar em que planos os discursos sobre serviços ecossistêmicos incorporam diferenças de outros sistemas: a) nos planos de códigos?; b) de estruturas?; c) dos programas? ou; d) das construções da realidade? (TEUBNER, 2005, p. 48).

A proposta é no sentido de que se devam construir concretamente hipóteses especulativas sobre as condições e tipos de normas jurídicas e suas respectivas formas de leitura (TEUBNER, 2005, p. 48-49). Em termos de serviços ecossistêmicos estas especulações científicas podem decorrer da Biologia, da Geografia, da Economia Ecológica e das Políticas Públicas de Pagamentos por Serviços Ambientais. 
Importante destacar que há uma sobreposição entre os conceitos de funções/processos e SE, tendo em vista que suas tipologias/classificações são arbitrárias e, portanto, existe uma liberdade para a construção de um sistema próprio de classificação, em conformidade com as necessidades de análise das pesquisas. Contudo, não se pode olvidar da perspectiva pluralista e transdisciplinar que deve trasnversalizar tanto as formas de observação culturais quanto as formas naturais dos ecossistemas. Tal forma permite a compreensão dos fluxos de serviços gerados por meio da contribuição de cientistas naturais como biólogos, ecólogos entre outros e cientistas sociais como antropólogos, economistas, cientistas sociais e políticos, juristas entre outros (ANDRADE, 2013, p. 67-68).

Portanto, a observação policontextural dos serviços ecossistêmicos necessita realizar-se com uma multiplicidade de diversos processos comunicativos e que se constituem reciprocamente. São advindos da Ciência, da Economia, da Política e se processam no Direito sob a codificação binária direito/não direito. A partir de uma teoria da autopoiese tal comunicação pode ser pensada sem que os limites do jurídico e do social se descaracterizem ao ponto de não serem reconhecidos (TEUBNER, 2005, p.83).

A sensitividade cognitiva dos serviços ecossistêmicos os desastres climáticos necessitam, portanto, de diferenciações trazidas pelas observações da Ciência, a da Política e da Economia, a partir de suas organizações e programas, para criar possibilidades de constituições recíprocas para assimilação e processamento e até auto fundação pelo Direito na constituição de legislação e decisões judiciais resilientes.

A aprendizagem por meio das comunicações assimiladas com o contexto da Ecologia dos ecossistemas possibilita a consideração pelo Direito sobre o "como" observar as características da vida biológica.

Os serviços ecossistêmicos, por se constituírem como resultados de funções ecossistêmicas, mantêm uma primeira relação de identificação causal direta de sua existência, manutenção e qualidade com a biodiversidade e podem ser classificados em três níveis: genética, de espécies e ecológica, sendo esta última o destaque desta reflexão. (BENSUSAN, 2008, p. 3).

A biodiversidade ecológica, para o enfoque deste estudo, diz respeito aos ecossistemas, ambientes e paisagens distintas que podem ser encontradas no planeta Terra. Cada um desses ambientes serve de habitat para uma diversidade de espécies e, por decorrência, uma diversidade genética, considerando as comunidades de animais, plantas e microrganismos abrigados nesses, além das múltiplas interações que conectam esses seres vivos entre si e com o seu entorno (BENSUSAN, 2008, p. 23-24). 
A Convenção sobre Diversidade Biológica da ONU de 1992, da qual o Brasil é signatário (BRASIL, 1998), assimila os três níveis de biodiversidade, constituindo-se em um documento paradigmático para a tomada de decisões notadamente econômicas, políticas e jurídicas.

Atualmente, o UNEP (2005) Programa da ONU para o Meio Ambiente, compreende a biodiversidade como a variabilidade entre os organismos vivos, incluindo a diversidade dentro de uma espécie, entre espécies, assim como internamente no ecossistema ou entre ecossistemas. 0 mesmo Programa considera a mesma como fonte de muitos bens ambientais (alimentos e recursos genéticos), salientando que mudanças podem influenciar na oferta de serviços oferecidos pelo(s) ecossistema(s).

Por sua vez, ecossistema é compreendido como um complexo dinâmico de comunidades vegetais, animais, microrganismos e seu respectivo meio, que interagem como uma unidade funcional. (UNEP, 2005, p. 49).

A produção de fenômenos emergentes assimilados como propriedades de um todo a partir da compreensão das partes, na estrutura de um ecossistema pode ser ilustrada, por exemplo, a partir da avaliação feita sobre a essencialidade que a Amazônia tem para a América do Sul e para todo o país atuando como o maior rio voador do mundo (NOBRE, 2016).

Destarte, os ecossistemas e suas funções proporcionam assim uma variedade de benefícios às populações humanas incluindo a infraestrutura essencial para a vida, tanto que em termos de classificação, o MEA os divide em quatro categorias, como de provisão, de regulação, culturais e de suporte, de acordo com sua relação com as populações humanas (MEA, 2005, p.39-40).

Tal classificação, orienta a compreensão dos serviços ecossistêmicos em múltiplas dimensões, ou seja, destaca-se que tais serviços adquirem o sentido de interação entre seres humanos e ecossistemas, prospectam o bem-estar humano a partir de um campo conceitual de "antropocentrismo alargado" ${ }^{2}$ e necessitam de avaliação processual ${ }^{3}$ e dinâmica dos impactos gerados pela sua conservação e/ou degradação.

\footnotetext{
${ }^{2}$ No Brasil esta expressão é utilizada por Leite na busca de uma possibilidade intermediária entre o antropocentrismo clássico (centrado exclusivamente na superioridade do homem em relação à natureza) e o biocentrismo (centrado na premissa de que todas as formas de vida detêm a mesma importância, não havendo distinção hierárquica entre a humanidade e os demais componentes da ecosfera que passariam de objeto a sujeitos de direito). Por sua vez, o antropocentrismo alargado trata o meio ambiente a partir de uma perspectiva que viabilize a proteção da sanidade ambiental para a sadia qualidade da vida em todas as suas formas, sejam humanas ou não. Assim, a referência a um ecossistema como uma unidade funcional de todos os organismos e seu meio deve ser interpretado pelo Direito como o conjunto de todos os seres humanos, desta e das futuras gerações, e os demais elementos bióticos e abióticos que compõem todos os ecossistemas, tomados de per si e/ou integrados (LEITE; 2003, p.76-77; LEITE; PERALTA, 2014, p.21).

3 "Cada processo, enquanto sistema temporário de interação, pode ser especificado funcionalmente, mas também diferenciado e estabelecido com autonomia relativa. Com isso ele adquire possibilidades próprias
} 
Ainda em termos ilustrativos é possível vislumbrar a relação entre alguns ambientes naturais como os marinhos cujas funções são as de manutenção da qualidade das águas, servir de habitar para plantas e animais, regular a composição atmosférica, a temperatura e a precipitação e prestar os serviços de tratamento/dispersão de efluentes, tratamento/dispersão de efluentes, produção de alimentos, sequestro de carbono, regulação do clima, turismo e recreação. Já as florestas exercem as funções de redenção de sedimentos, regulação das águas, alimentação das águas subterrâneas, habitat para plantas e animais, regulação da temperatura e precipitação e prestam serviços como retenção de sedimentos, controle de enchentes, fornecimento de água, produção de alimentos, madeira, fibras e polinização, sequestro de carbono, regulação do clima, turismo e recreação ( CONSTANZA et al, 1997, p. 253-260).

Existem ainda ambientes como os campos cujas função são as de reter sedimentos, servir de habitat para plantas e animais, regular a composição atmosférica, a temperatura e a precipitação e prestam serviços como a produção de alimentos, polinização, sequestro de carbono, regulação do clima, turismo e recreação. As áreas úmidas como banhados, mangues e pântanos exercem funções como as de manter a qualidade e regular as águas, alimentar e servir de descarga para as águas subterrâneas, habitat para plantas e animais, regular a composição atmosférica, temperatura e precipitação. Por sua vez, prestam os serviços de tratamento/dispersão de efluentes, controle de enchentes, suprimento de água, produção de alimentos, sequestro de carbono, regulação do clima, turismo e recreação. Rios e Lagos também exercem funções como as de manter a qualidade das águas, alimentar e servir de descarga para as águas subterrâneas, habitat para plantas e animais, regular a temperatura e precipitação e de ambiente natural. Também prestam serviços como os de tratamento/dispersão de efluentes, suprimento de água, produção de alimentos, regulação do clima e turismo e recreação (CONSTANZA et al, 1997, p. 253-260).

Enfim, a Ecologia tem a possibilidade de fornecer ainda muitos subsídios de aprendizagem em relação aos serviços ecossistêmicos tanto no que diz respeito ao seu uso como em relação ao seu valor. Contudo, sua manutenção irá requerer um conhecimento consideravelmente melhor dos padrões e processos naturais que os sustentam. Uma pesquisa inovadora deve ser iniciada para responder a questões cruciais como: a) quais serviços ecológicos são insubstituíveis ou demasiado caros para serem substituídos por tecnologia emergente?; b) quais habitats precisam ser protegidos para assegurar que os serviços básicos sejam providos?; c) quais agentes comprometem e degradam

e uma temática também própria, com regras especiais sobre a relevância ou irrelevância, assumindo, nesses limites, uma margem de possibilidades, a correspondente incerteza e uma história própria que absorve essa incerteza." (LUHMANN, 1983. p.178). 
os serviços ecossistêmicos e como seus impactos podem ser evitados ou mitigados?; d) de que maneira as decisões individuais, corporativas e governamentais sustentam ou degradam os serviços ecossistêmicos? (PALMER, 2004, p. 1251).

As contribuições da Ecologia abrem possibilidades ao Direito para assimilação dos serviços ecossistêmicos na perspectiva de um antropocentrismo alargado, incluindo as futuras gerações, bem como a necessidade de identificação dos seus benefícios diretos e indiretos, métodos para mapear, avaliar e gerir esse capital natural com horizontes de precaução, prevenção e mitigação de desastres ambientais/climáticos.

Contudo, é preciso considerar que a Ecologia também comunica desafios em relação aos ecossistemas e seus serviços, como a necessidade de compreensão sobre a complexidade dinâmica e adaptativa dos ecossistemas e suas alterações funcionais, o que implica em constante alteração funcional. Neste sentido leis e decisões judiciais precisam gerir tal compreensão de dinamicidade. Um segundo desafio direciona-se para a necessidade de que a Ecologia precisa considerar as fronteiras (limites) ${ }^{4}$ dos ecossistemas e os seus serviços para que subsistemas sociais como a Economia, a Política e o Direito possam construir no interior de suas organizações processos direcionados à decisões de proteção e de recuperação ${ }^{5}$ dos ecossistemas e de seus serviços, a despeito de incertezas científicas.

Ainda para uma gestão circular dos desastres climáticos, como se propõe a atual Política Nacional de Proteção e Defesa Civil o Direito necessita ainda de elementos de outro contexto social que é a Ciência, caso a possibilidade escolhida seja orientada pelo critério da territorialidade. Nesta perspectiva na proporção que examina em profundidade os processos sociais que geram paisagens, onde a influência humana é fundamental, a geografia assume papel para a importância da análise dos padrões de uso da terra na geração dos serviços ecossistêmicos.

A influência das relações da geografia e das características de ecossistemas no desdobramento da história humana pode ser observada na análise que faz sobre a interação entre

\footnotetext{
${ }^{4}$ Nesta construção de sentido, os limites não se relacionam à teoria dos sistemas, mas refere-se à possibilidade de traçar territórios onde as funções de ecossistemas ficaram melhor delimitadas ou ainda traçar a trajetória entre os ecossistemas produtores de SE até seus usuários, mesmo considerando incertezas científicas.

${ }^{5}$ Em ecologia a restauração de ambientes degradados enfatiza o restabelecimento de comunidades originais de plantas, fungos e bactérias que agem na decomposição de matéria orgânica e ciclagem de nutrientes. Os invertebrados são também importantes para a criação de estrutura do solo e herbívoros, além de herbívaros que reduzem a competição vegetal e com isso garantem a diversidade de plantas. Muitos invertebrados são dispersores de sementes, predadores de insetos e escavadores de solos. Tais espécies podem ser levadas para as áreas degradadas em torrões de terra. Animais maiores e invertebrados podem ser capturados em quantidade, para então serem liberados nas áreas. Nos locais onde a degradação possa ser planejada antecipadamente deve-se recolher o horizonte superficial do solo, que contém a maior das sementes, invertebrados e outros organismos para serem utilizados na restauração (PRIMACK; RODRIGUES, 2001).
} 
os processos sociais e as condições ecológicas. Sociedades históricas tais como a da llha de Páscoa e a dos Maias desabaram quando o capital natural se esgotou pela ação humana e os SE falharam e outras, modernas como as do Haiti e a da China sofrem ameaça de colapso, seja pela precária administração de seus recursos naturais, seja pelo crescimento da população e da economia, fatores estes que estão destruindo um capital natural necessário a produção de processos ecológicos, funções e serviços ecossistêmicos ( DIAMOND, 2013, p. 105-152; 195-218; 397-452).

Assim, as relações sociais e as mudanças na ecologia passam a assumir destaque para uma geografia que se torna mais complexa ao assimilar questões relativas ao investimento em capital natural, sua manutenção, depreciação ou até liquidação.

Ao se tratar de um conceito baseado no antropocentrismo, os serviços ecossistêmicos são dramaticamente afetados pela presença humana e pelo seu uso e não apenas pelo abuso. Assim, a contribuição dos serviços ecossistêmicos para prevenção e mitigação de desastres climáticos requer a observação da geografia no que se refere à degradação humana dos ecossistemas e a consequente vulnerabilidade social, bem como as complexidades geográficas na identificação dos mesmos, além das relações espaciais e temporais dos ecossistemas.

Para a gestão do risco climático pelo Direito são necessárias as conexões que direcionam os serviços ecossistêmicos às populações humanas destacadamente as que possibilitam maior sensitividade para assimilações como: a) influência da ação humana na perda da biodiversidade e degradação dos ecossistemas e seus serviços; b) complexidades geográficas na identificação de benefícios indiretos dos serviços ecossistêmicos para mitigação e prevenção de desastres climáticos e; c) as escalas espaciais e temporais e panarquias dos ecossistemas.

Atualmente as taxas de extinções de ecossistemas e seus benefícios pelo desmatamento e por destruições de outros habitats indicam que a Terra está em meio a um evento único de extinção em massa, não só pela sua magnitude como pela sua causa, pois enquanto as extinções anteriores foram causadas por fenômenos físicos naturais, a atual extinção em massa está sendo causada, pela primeira vez, pelas atividades de uma única espécie, ou seja, o homem (CAPRA, 2014, p.434).

Assim, a análise da intervenção das populações humanas nos serviços ecossistêmicos e a estreita relação com os impactos das mudanças climáticas permitem que a Geografia assuma destaque pela pesquisa realizada pelo MEA (2005, p. 2-3) que conclui que nos recentes últimos cinquenta $\operatorname{anos}^{6}$ a degradação dos ecossistemas no planeta foi tão rápida e extensa que é impossível compará-la a qualquer período de tempo na história humana. Isso ocorreu, para atender demandas

\footnotetext{
${ }^{6}$ À expressão "últimos cinquenta anos" referem-se ao período anterior à realização da pesquisa pelo MEA, ou seja, entre 2001-2005.
} 
de crescimento rápido por alimentos, água potável, madeiras, fibras e combustível, o que permite a conclusão de que a intervenção humana é considerada a maior responsável por uma perda substancial e irreversível de grande parte da biodiversidade no planeta e, consequentemente, dos serviços ecossistêmicos.

A utilização indiscriminada dos bens ambientais nos dois últimos séculos causou uma perda significativa da diversidade biológica tanto que, ilustrativamente, a destruição, fragmentação e degradação de ecossistemas comprometem suas funções, sintetizam causas de extinção ambiental, impactam nos serviços ecossistêmicos, provocando o aumento de doenças e as alterações no clima provocam mudanças na distribuição e migração de espécies (PRIMACK; RORIGUES, 2005, p. 33; MEA, 2005).

É igualmente certo afirmar que as intervenções realizadas nos ecossistemas contribuíram para ganhos substanciais em relação ao bem-estar humano e ao desenvolvimento econômico. Contudo, tais benefícios foram obtidos a um custo de crescente degradação de diversos serviços prestados pelos ecossistemas, aumentando os riscos de mudanças irreversíveis e exacerbando a pobreza de grupos sociais vulneráveis. Se tal conjuntura não for enfrentada, haverá uma diminuição substancial nos benefícios que os ecossistemas prestarão às futuras gerações.

Em termos de horizonte de futuro, há a projeção de que o processo de degradação se agrave durante a primeira metade deste século, constituindo-se um desafio reverter a degradação dos ecossistemas e continuar atendendo, mesmo que parcialmente, a crescente demanda por seus serviços. Para tanto é necessário e urgente projetar cenários de mudanças significativas nas decisões políticas e suas organizações o que ainda não ocorreu. De outra perspectiva a incerteza não pode justificar a inércia política, uma vez que a ciência já dispõe de possibilidades para manutenção, conservação e otimização dos serviços prestados pelos serviços ecossistêmicos (MEA, 2005, p.1).

Portanto é necessário partir de um ponto irrefutável, ou seja, admitir que as ações humanas estão esgotando o capital natural da terra e causando pressão sobre o meio ambiente, de forma que já não se pode garantir a capacidade dos ecossistemas do planeta para sustentar as futuras gerações, caso não sejam tomadas decisões substanciais nos próximos cinquenta anos ( MEA, 2005, p. 1-2).

Outro fator que assume cada vez mais influência para a biodiversidade e desestabilizam, por consequência, a prestação dos serviços ecossistêmicos são as mudanças previstas nos padrões de temperatura e pluviosidade ao redor do mundo. As mudanças nas condições ambientais afetarão o tamanho e a localização de áreas habitáveis das espécies, estejam ou não em risco de extinção no presente. Acresce-se ainda o fato de que as reservas naturais poderão passar a estar no lugar errado. Assim, modelos de mudança climática global podem ser usados pelos ecólogos para salvar as 
espécies e comunidades no momento do planejamento da conservação de espécies individuais ou do delineamento de redes de reservas (TOWNSEND; BEGON; HARPER, 2010, p. 539).

Além da importância que assume a constatação da intervenção humana na degradação e perda de serviços ecossistêmicos, outra comunicação que advém da geografia adquire sensitividade ao considerar estágios da gestão cíclica dos desastres climáticos pelo Direito. Trata-se da complexa identificação e mapeamento da direção entre os serviços ecossistêmicos e os seus destinatários como possibilidade de aprendizagem e planejamento para o futuro.

As contribuições da geologia e da hidrologia nos estudos por escalas apresenta-se como valioso subsídio na elaboração de instrumentos como a Carta Geotécnica de Aptidão Urbanística para identificar e mapear "zonas úmidas". ${ }^{7}$

A identificação, mapeamento e preservação das zonas úmidas nas áreas urbanas contribuem para a percepção sobre sua maior importância em relação ao avanço de ocupação imobiliária. Estas oferecem os serviços ecossistêmicos de manutenção da umidade e produção de água em períodos de escassez (secas), assim como proporcionam a absorção mais rápida da água pelo solo nos eventos de inundações bruscas, diminuindo alagamentos.

As escalas especiais e temporais devem assim integrar as Cartas Geotécnicas de Aptidão Urbanística, Planos Diretores Municipais e Códigos de Edificações na identificação, mapeamento e gerenciamento de áreas, cujo benefícios dos ecossistemas em relação à prevenção de desastres climáticos justifiquem a imposição normativa ou por decisão judicial de sua recuperação, preservação ou para consolidação complexa, ${ }^{8}$ ou seja, com restrições para edificações ou quanto ao uso do solo.

A relevância da escala para a autopoise do Direito e da Política reside na possibilidade de escolha de um subsídio com parâmetros científicos e não meramente retóricos na descrição da cadeia que vai desde a fonte de produção até o usuário do serviço ecossistêmico. Isto requer uma profunda compreensão da Ecologia e de como das escalas espaciais e temporais na Geologia e Hidrologia devem operar (RUHL; KRAFT; LANT, 2007, p.48).

As escalas espaciais e temporais dos serviços ecossistêmicos, estes assimilados como processos ecológicos adaptativos, se relacionam tendo por referência um modelo científico descrito

\footnotetext{
${ }^{7}$ A expressão zona úmida indica a identificação à disponibilidade, a saturação e o acúmulo de água no solo. Relaciona-se com a profundidade do lençol freático na mancha HAND- Jeight Above the Nearest Drainage, ou seja, altura acima da drenagem mais próxima. Do ponto de vista de desastres climáticos está associada aos processos de inundação (áreas de planície), bem como incorpora as zonas ripárias (oriundas das faixas de APP), que sendo ocupadas ou não, afetam a dinâmica de uma bacia hidrográfica, inclusive em períodos de estiagem ( MOMM, 2016).

${ }^{8}$ Consolidação complexa - termo utilizado para as restrições de edificações quanto ao uso do solo.
} 
como panarquia (HOLLING et al, 2004). Tal modelo relacional é compreendido como um dos atributos da resiliência e considera que as relações de processos ecológicos não estão agrupadas como unidades hierárquicas, mas constituem-se como ciclos de adaptação inter-relacionados em que cada nível de um processo é influenciado por todos ou alguns dos ciclos de outros níveis de

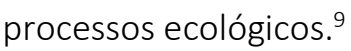

Assim, por meio da diferenciação de funções dos serviços ecossistêmicos é que se pode motivar o reconhecimento das consequências da seleção de escalas, ou seja, se o propósito dos mesmos é a prevenção e a mitigação de desastres climáticos a consideração de escalas espaciais e temporais assume relevância. Para a Política tal relevância pode ser refletida na formulação de políticas públicas ambientais e até de atos administrativos. Para o Direito refletem na interpretação de leis e construção de decisões que sejam operativas aos estágios de prevenção, compensação e reconstrução no gerenciamento cíclico de desastres.

A avaliação dos serviços ecossistêmicos não pode, portanto, prescindir da Geografia, pois processos ecológicos operam em uma amplitude que inclui escalas temporais e espaciais (CHRISTENSEN et al., 1996, p. 666). A compreensão de tal interação é relevante para a tomada de decisões em relação aos serviços ecossistêmicos, embora seja muito complexa a análise, com maior destaque ainda ao se projetar os benefícios dos mesmos em relação à mitigação e prevenção de desastres climáticos em escalas espaciais regionais (ou sub globais) e globais ( MEA, 2005, p. 84-91).

Finalmente um terceiro ponto de observação complementar da Geografia refere-se às interações sociais, políticas, jurídicas e econômicas dos serviços ecossistêmicos nas escolhas das escalas de estudos.

As escalas espaciais relacionam-se com as escalas temporais, ou seja, é preciso considerar que as formas espaciais de um serviço ecossistêmico mudam com o tempo na proporção que os ciclos adaptativos ocorrem e os limites dos ecossistemas vão se (re)construindo.

A coexistência entre o espaço/tempo e sua correlação denomina o que a Geografia estuda como "domínio escala" que unifica modelos espaciais e temporais de observação dos SE. Isto permite a assimilação de que a percepção do risco climático precisa considerar os efeitos cumulativos $^{10}$ que nem sempre trazem impactos visíveis e rápidos em relação aos benefícios indiretos fornecidos pelos serviços ecossistêmicos.

\footnotetext{
${ }^{9}$ Em uma panarquia, construída em distinção com a hierarquia, os fenômenos de uma larga escala ocorrem como propriedade emergentes de fenômenos de pequena escala, mas em compensação também fornecem condições estruturais e restrições sobre fenômenos de menor escala (RUHL; KRAFT; LANT, 2007. p.50).

${ }^{10}$ Efeitos cumulativos envolvem a junção de inúmeras ações com pequenos efeitos em um domínio de escala que impactam significativamente outra escala de domínio. Em termos de exemplo pode-se citar a lenta
} 
Portanto, a geografia dos serviços ecossistêmicos assume destaque ao comunicar aos outros contextos como o da Política e o do Direito a necessidade de considerá-los como produtos de processos ecológicos adaptativos que precisam ser observados integrativamente em escalas espaciais e temporais.

É preciso considerar que evoluir a partir das comunicações vindas da Ciência (Ecologia, Geografia, Geologia e Hidrologia) constitui-se um desafio gerador de grande complexidade na construção de habilidades no interior das organizações. Destarte organizações resilientes precisam compreender, assimilar e processar o mapeamento dos serviços ecossistêmicos desde suas fontes até os seus usuários, assim como as relações de escalas espaciais e temporais o que, por seu turno, exigem um detalhamento de outro componente contextual na gestão de desastres climáticos pelo Direito, ou seja, o contexto da Economia.

A valoração dos serviços ecossistêmicos pela Economia não é atribuída apenas pela sua importância à vida e infraestrutura necessárias para o estabelecimento das sociedades, mas também pelo valor infinito que assumem quando mensurados em relação ao estoque de recursos naturais cada vez mais escassos no planeta (HEAL, 2000).

É no contexto da Economia Ecológica, uma subdisciplina da Economia, que o complexo leque de SE que se encontram em um ecossistema assume relevado destaque, com a finalidade de identificar os bens e serviços, quantificá-los em seu valor e torná-los compreensíveis para subsidiar decisões políticas e jurídicas, notadamente em relação aqueles cuja perda não seria possível suportar (VERCHICK, 2010, p.23).

Para fins de valoração de serviços produzidos pela natureza devem ser considerados tanto os que são proporcionados aos seres humanos por ecossistemas naturais, quanto aqueles os que são oferecidos por ecossistemas manejados ativamente pelo homem (MURADIAN, 2010, p.12021208). Na Economia Ecológica ${ }^{11}$ o foco não consiste em identificar a valoração econômica dos

acumulação de dióxido de carbono e metano devido à queima de combustível fóssil e certas atividades agrícolas. Neste caso cada automóvel, fazendo do arroz, cabeça de gado e consumidor de eletricidade, de forma individual, impactam minimamente o clima, embora agregados ao longo de décadas e séculos, o impacto seja profundo. (RUHL; KRAFT; LANT, 2007, p. 54).

${ }^{11}$ A necessidade da valoração ambiental é discutida e aceita tanto pelos autores da Economia Ambiental quanto da Economia Ecológica. Para as duas abordagens, a valoração econômica dos bens e serviços gerados pelo ecossistema tem uma importância muito grande. O problema está nos fundamentos e objetivos da valoração. Enquanto a Economia Ambiental utiliza os fundamentos neoclássicos de equilíbrio, racionalidade e utilitarismo e, por isso, é tão criticada, a Economia Ecológica busca valorar os recursos naturais através de uma maior interação entre a economia e a ecologia. Diante disso, os modelos econômicos e ecológicos tradicionais não seriam capazes de englobar todas as interações entre a economia e a ecologia (ROMEIRO, 2012, p.65-92). 
serviços ecossistêmicos para motivar um comportamento econômico tal como o investimento, a produção, a aquisição, a manutenção ou a proteção.

Para os serviços ecossistêmicos a administração circular dos desastres climáticos pela Economia necessita integrar valores conservacionistas, de ordenação e de planejamento de ocupação do solo, gestão do crescimento e planejamento da infraestrutura construída (ou cinza). A partir desse processo integrativo se possibilita conceber cidades com a criação de espaços interconectados de áreas naturais e outros espaços abertos protegidos que promovem benefícios ecológicos de prevenção e precaução à sociedade e ao ambiente, diminuindo as vulnerabilidades e promovendo a construção de resiliência.

Assim, a gestão dos desastres climáticos pelo Direito centra-se, na possibilidade de construção de um sentido de infraestrutura verde ou natural, que atribui destaque às áreas ambientalmente relevantes para a qualidade de vida nas cidades. Esta observação permite a abertura da possibilidade de criação de uma rede interconectada de espaços ambientais que conservam valores e funções ecossistêmicas, provendo benefícios associados às comunidades vulneráveis aos riscos climáticos (CARVALHO, 2014, p.52).

\section{POLÍTICAS PÚBLICAS DE PAGAMENTO POR SERVIÇOS ECOSSISTÊMICOS E SUA ORIENTAÇÃO À GESTÃO DE RISCOS DE DESASTRES NO BRASIL}

A contribuição dos serviços ecossistêmicos em relação aos desastres climáticos pode ser visualizada, de forma ilustrativa, por banhados, florestas e sistemas costeiros (recifes de corais e ervas marinhas). Os mesmos servem como barreiras protetivas naturais ou amortecedores para minimizar impactos, bem como reduzir vulnerabilidades socioeconômicas inerentes aos riscos, construindo resiliência antes, durante e após o evento por meio de suprimentos como água, abrigo e alimento. Portanto, os desastres climáticos passaram a exercer um papel significativo para determinar como se entende e valora os ecossistemas e seus serviços PARTNERSHIP FOR ENVIRONMENT AND DISASTER RISK REDUCTION, 2015, p.3).

O Pagamento por Serviços Ambientais apresenta-se como um instrumento econômico com a finalidade de recompensar quem produz ou mantêm os serviços ambientais atuais ou incentivar outros a garantirem o seu provimento e que não o fariam sem o incentivo (GUEDES, SEEHUSEN, 2011). Com o mecanismo, busca-se mudar a estrutura de incentivos de forma a melhorar a 
rentabilidade relativa das atividades de proteção e uso sustentável de recursos naturais em comparação com atividades não desejadas, seguindo o princípio do "protetor-recebedor " ${ }^{12}$

O Pagamento por Serviços Ambientais é um instrumento multifuncional pois, além da proteção ambiental em si mesma considerada, abre a possibilidade de tornar-se aplicável e plenamente integrado ao enfrentamento dos desastres.

Além da definição do bem ambiental fornecido por um ou mais ecossistemas, os métodos de valoração econômica precisam considerar a geografia (notadamente a geologia e hidrologia) com suas escalas espaciais e temporais. Isto significa que uma avaliação de custo de transação precisa obedecer também a um critério de territorialidade e temporalidade. O Pagamento por Serviços Ambientais necessita assim utilizar instrumentais econômicos que assimile os serviços ecossistêmicos, segundo uma diferenciação funcional que conecte o tipo de benefício de um ecossistema biologicamente dinâmico-evolutivo, considerando escalas espaciais e temporais. Tratase, portanto, de uma alta complexidade para operacionalidade jurídica voltada à prevenção e mitigação dos desastres.

Para efeitos de desastres climáticos, uma das possibilidades é afirmar que a complexidade reside na construção de um método de avaliação econômica que parta da função ecológica preventiva e/ou mitigatória de um ou mais ecossistemas que operam em escalas espacial e temporal, como uma rede de infraestrutura natural. Tal rede precisa ser comparada com a avaliação econômica dos custos dos benefícios de prevenção e/ou mitigação que são oferecidos por uma infraestrutura "cinza" ou construída. Mas não é só, pois a tal comparação ainda precisa ser agregada a variável de identificação dos beneficiários (demanda) e a comparação aos provedores dos serviços ecossistêmicos.

Em nível nacional, contudo, o pioneirismo em experiência de pagamento por serviços ambientais consiste no uso de um instrumental da Economia para incentivo da proteção ambiental. Por decorrência de tal instrumental há uma demanda para estabelecimento de um marco legal no país sobre tais práticas, considerando o processo já iniciado em diversos estados da federação por meio de implantação de políticas públicas estaduais e municipais.

A valoração dos serviços ecossistêmicos em relação aos desastres precisa e diferenciar enquanto função que assimila benefícios que são oferecidos por funções de um ou de diversos

\footnotetext{
12 O princípio do protetor-recebedor propõe o pagamento àqueles agentes cuja ação promove o incremento dos SE prestados pela natureza. Apresenta-se com base na ideia de "ajuda" à natureza, justificado sob o fundamento de que as práticas humanas podem degradar ou destruir as condições de prestação do serviço ou podem, ao contrário, reforça-las e protege-las, merecendo então uma compensação( NUSDEO, 2012, p. 137).
} 
ecossistemas. Desta forma reconfigura-se para se constituir como estrutura natural que instrumentaliza a Política e o Direito em todos os estágios da gestão dos desastres climáticos.

As políticas públicas de Pagamento por Serviços Ambientais, em âmbito estadual e municipal do contexto político nacional, apresentam-se como formulações recentes de decisões da Política em tentar estabilizar expectativas crescentes que foram assimiladas e que podem ser objeto de reflexão.

No âmbito da Política a gestão dos desastres climáticos a partir da integração dos serviços ecossistêmicos requer uma compreensão reflexiva de que é preciso construir uma estrutura apta a aprender com desastres já ocorridos, avaliar as vulnerabilidades sócio ambientais, decidir sobre os instrumentos que melhor se adaptam à reconstrução do território e, sobretudo, prospectar um futuro que possa enfrentar com criatividade a crescente recorrência, severidade e intensidade de eventos climáticos com potencial catastrófico.

A responsabilidade das organizações deve consistir na execução, controle e fiscalização de suas operações de gestão de desastres climáticos. Por sua vez, o caráter multifacetado que caracteriza grande parte dos desastres ambientais requer uma multidisciplinaridade nos processos de decisão (CARVALHO, DAMACENA, 2013, p.96). Igualmente requer uma integração entre atores públicos e privados, constituindo-se em uma governança de riscos climáticos, considerando que desastres, via de regra, estão vinculados a um déficit de proteção ambiental, de segurança pública, ou de atendimento da defesa civil.

No âmbito internacional as mudanças climáticas têm gerado reações de organizações políticas internacionais na tentativa de sensibilizar atores políticos a adotarem medidas de enfrentamento, como é o caso da COP-21 no sentido de impulsionar a ratificação do Acordo de Paris (ANGELO, 2016).

Já no contexto nacional, um primeiro filtro de introdução da temática na Política é dado pela compreensão do artigo no 225, §1, I e II da CF/1988, em que a responsabilidade pela preservação do meio ambiente ecologicamente equilibrado, para as atuais e futuras gerações, deve ser compartilhada entre o Poder Público e a coletividade, mas compete ao primeiro preservar e restaurar os processos ecológicos essenciais, a biodiversidade e prover o manejo ecológico das espécies e ecossistemas, devido justamente ao poder de polícia que detém a Administração Pública ( BRASIL, 1988).

Ademais, a recorrência e severidade dos desastres climáticos das últimas décadas acrescentaram relevância à temática na agenda política de forma que eventos catastróficos têm gerado expectativas na opinião pública quanto à tomada de decisões do Estado e de suas organizações com fins de apresentar uma estabilização para tal complexidade. 
Nesse sentido, a instrumentalização de políticas públicas municipais e estaduais vem assimilando a relevância dos serviços ecossistêmicos por meio do Pagamento por Serviços Ambientais e Programas por Incentivos Ambientais, em atendimento a escalas preponderantemente espaciais como Bacias Hidrográficas, por exemplo, e delimitadas, na sua grande maioria, no âmbito de divisão político administrativo do território.

Contudo, há possibilidades de delinear um ecossistema para fins de proteção, sem violar sensibilidades científicas. Para tanto, é preciso enfrentar quatro variáveis científicas e considerar: a) que dentro de um grande ecossistema podem existir diversos menores; b) que os ecossistemas são interligados e podem oferecer dificuldades em separá-los; c) que os limites dos ecossistemas se expandem e contraem ao longo do tempo em resposta a influências naturais e antropogênicas, e; c) que os ecossistemas são entidades estabelecidas mais ecologicamente do que legislativa ou administrativamente (RUHL; KRAFT; LANT, 2007, p.21-22).

Um método promissor para operacionalizar o delineamento de um ecossistema é conhecido como "fatores controladores" que implica em identificar fatores-chaves que influenciam decisivamente nos processos ecológicos e utilizá-los para divisão em unidades ecológicas. Tal método apresenta-se como vantajoso para permitir maior simplificação, padronização e verificação para que a Política possa assimilar o gerenciamento dos ecossistemas (RUHL; KRAFT; LANT, 2007, p.22).

Portanto, os diferentes contextos de análise dos serviços ecossistêmicos podem se integrar ao uma comunicação jurídica cognitiva sobre a gestão de desastres, justamente visando uma construção operacional via intepretação legislativa e decisões judiciais, sendo esta a abordagem do título seguinte.

INTERCONEXÕES ENTRE A POLÍTICA NACIONAL DE PROTEÇÃO E DEFESA CIVIL E O ESTATUTO DA METRÓPOLE: OS SERVIÇOS ECOSSISTÊMICOS COMO POSSIBILIDADE COMUNICATIVA

O marco legal sobre desastres no Brasil estrutura-se na forma da Política Nacional de Proteção e Defesa Civil -PNPDEC- preconizada pela Lei no 12.608/2012 que, por sua vez, recepcionou parcialmente legislações anteriores como o Decreto № 7.257/2010 e a Lei № 12.340/2010 e pontualmente foi complementada pela Lei no 12.983/2014.

As normas sobre Defesa Civil, anteriores à PNPDEC- Lei no 12.608/12- centravam-se histórica e preponderantemente em estratégias de respostas emergenciais aos desastres e ações direcionadas ao restabelecimento da antiga normalidade no momento pós-desastres. (CARVALHO e DAMACENA, 2013, p.68). Predominantemente se constituíam em formas lineares de gestão e 
careciam da necessária circularidade e gerenciamento dos riscos de desastres entre os diversos estágios ou fases dos eventos catastróficos, pois sua eficácia convergia para ações de respostas.

O tema "desastres" na Lei no 12.608/12 abarca em seu conteúdo a superação da dogmática ambiental tradicional sobre riscos concretos e inclui no artigo $2 \circ$, $\S 2$ 으 os termos incerteza e risco, abrindo a possibilidade de que esta política pública chancele também a precaução como base fundante de um sistema de enfrentamento de desastres (BRASIL, 2012). Isto significa que havendo pouca probabilidade de ocorrer um desastre, mesmo não existindo plena certeza científica a respeito da possibilidade de ocorrência futura ou dos possíveis efeitos decorrentes de sua concretização, ainda assim devem ser consideradas e planejadas ações para evitá-lo ou mitigá-lo, ou seja, de minimização de possíveis riscos.

Para consecução dos princípios da PNPDEC - Lei no 12.608/2012, são elencadas seis diretrizes para a União, Estados, Distrito Federal e Municípios, segundo suas esferas de atuação. Enquanto no nível federal elas devem ser tratadas de forma orientativa e estratégica, nos níveis estadual e municipal passam a ter cunho mais operacional.

A atuação articulada entre União, Estados, o Distrito Federal e os Municípios para redução de desastres e apoio às comunidades atingidas diz respeito a uma forma de gestão que precisa estabelecer canais de comunicação e integração de ações entre os diferentes níveis de governo, com vistas a ampliar a capacidade de prevenir riscos, de reduzir desastres e de dar melhor resposta, no caso de ocorrência de desastres. Tal articulação racionaliza e otimiza recursos, bem como melhora a avaliação dos riscos, posto que muitos eventos extrapolam os limites territoriais de Municípios ou Estados da federação.

Uma das diretrizes se refere à priorização das ações preventivas relacionadas à minimização de desastres, o que significa que a prevenção também é uma ação estratégica. A ações de prevenção devem ser prioritárias e deixam de ter como único destaque a ocorrência do desastre. Em outras palavras, ainda que alguns eventos catastróficos não possam ser evitados, o ideal é que não causem danos, ou que os danos causem poucas irreversibilidades. Portanto, o texto da lei dá forte ênfase às ações preventivas, reduzindo ou minimizando as causas de desastres e promovendo ações que tornem as comunidades menos vulneráveis e mais resilientes aos desastres absolutamente inevitáveis.

São estes dois pontos, ou seja, a atuação articulada entre os entes federativos e prevenção como forma motriz que torna possível uma relação comunicativa entre a gestão dos desastres por serviços ecossistêmicos e o Estatuto da Metrópole (BRASIL, 2015) que prevê na elaboração do Plano de Desenvolvimento Urbano Integrado o Pagamento por Serviços Ambientais. Esta é uma 
perspectiva que requer planejamento e gestão interfederativa e, para a gestão de desastres, apresenta-se como inovação e um instrumento valioso para mitigação e prevenção, especialmente nas áreas mais vulneráveis aos danos como é o caso das regiões metropolitanos e aglomerados urbanos.

Em termos de programas, os governos, organizações políticas e comunidades, as metrópoles e aglomerados urbanos contam com instrumentos contidos no Estatuto da Cidade - Lei nำ10.257/2001, Estatuto da Metrópole- Lei no 13.089/15 e PNPDEC - Lei no 12.608/2012 que podem interagir e garantir ações estratégias para implementação de uma política de inclusão da infraestrutura natural oferecida pelos serviços ecossistêmicos na reconstrução, cujo horizonte deve ser a prevenção e mitigação de desastres futuros.

Apesar da evolução legislativa, o processo de decisão política ainda se mostra lento, tanto que ao se tomar o caso de programas de políticas ambientais na grande metrópole de São Paulo, por exemplo, considera que a escala de intervenções realizadas por organizações políticas ainda é pequena. Os resultados em termos de impactos positivos, principalmente no que concerne a drenagem, aumento de áreas verdes e da qualidade da água existem, mas são muito pontuais do ponto de vista do território de atuação (TRAVASSOS, 2014, p.122).

Da mesma forma, o mesmo exemplo demonstra que as questões habitacionais não possuem indicadores satisfatórios, destacadamente porque em algumas reurbanizações a quantidade de remoções é maior que a quantidade de unidades habitacionais construídas. Tais indicadores implicam na consideração de que parcela significativa das famílias, provavelmente irão habitar em outro assentamento precário, no próprio município ou nos outros municípios da Região Metropolitana (TRAVASSOS, 2014, p.122-123). Isto demonstra a baixa capacidade do poder público (Estado e organizações políticas) em intervir no preço da terra urbana e sua destinação, bem como a insuficiência ou falta de regulamentação de instrumentos contidos no Estatuto da Cidade pela Lei ํㅡ 10.257/2001.

O Estatuto da Metrópole da Lei № 13.089/2015, acresceu instrumentos e inovações em gestão de funções públicas de interesse comum em regiões metropolitanas ou aglomerados Urbanos entre elas a governança de serviços ecossistêmicos, mas trata-se ainda de um processo em construção considerando a história recente de promulgação da referida Lei.

O Plano de Desenvolvimento Urbano Integrado inserido no Estatuto da Metrópole apresenta-se igualmente como possiblidade de instrumentalização pela Política no âmbito das regiões metropolitanas e aglomerados urbanos, uma vez que para sua elaboração a Lei no 13.89/2015 exige diretrizes mínimas que destacam a gestão de desastres climáticos. Tais diretrizes 
incluem: a) funções públicas de interesse comum, incluindo projetos estratégicos e ações prioritárias para investimentos; b)o macrozoneamento da unidade territorial urbana; c) formas de articulação dos Municípios no parcelamento, uso e ocupação no solo urbano e articulação intersetorial das políticas públicas afetas à unidade territorial urbana; d) delimitação das áreas com restrições à urbanização visando à proteção do patrimônio ambiental ou cultural, bem como das áreas sujeitas a controle especial pelo risco de desastres naturais; e) sistema de acompanhamento e controle de suas disposições. ${ }^{13}$

De forma integrativa, a Política Nacional de Proteção e Defesa Civil (Lei no 12.608/2012), atribuiu instrumentalidade multifuncional de programas governamentais locais e de políticas públicas (ambientais, urbanas e rurais) em que os serviços ecossistêmicos são assimilados como elementos essenciais na gestão de desastres pela Política como, por exemplo a contribuição da geologia e da hidrologia nas Cartas Geotécnicas de Aptidão Urbanística, parcelamento do solo, direito de propriedade e restrições ao seu uso pelos planos diretores municipais, educação ambiental, saúde pública, gestão de recursos hídricos pelo Plano de Recursos Hídricos ( por Bacias Hidrográficas).

Portanto, é nesta configuração de Estado que as estruturas públicas e privadas enfrentam os riscos climáticos catastróficos, mediante uma tríplice base que inclui a gestão de riscos, conjuntamente com a prevenção e a integração das políticas de ordenamento territorial, desenvolvimento urbano, saúde, meio ambiente, mudanças climáticas, gestão de recursos hídricos, geologia, infraestrutura, educação, ciência e tecnologia e demais políticas setoriais ( CARVALHO; DAMACENA, 2013, p.1).

\section{CONCLUSÃO}

A gestão dos desastres climáticos pelo Direito necessita centra-se na possibilidade de construção de um sentido jurídico de infraestrutura verde ou natural que destaca áreas ambientalmente relevantes para a qualidade de vida nas cidades agregadas à função de prevenir ou mitigar o risco de desastres.

Por seu turno, elementos de outros contextos da Ciência, da Política e da Economia sobre serviços ecossistêmicos oferecem condições de serem parametrizados e assimilados pelo Direito, tanto na interpretação do contexto jurídico nacional como na construção de decisões judiciais que ofereçam possibilidades de prevenir ou mitigar os riscos de desastres.

\footnotetext{
${ }^{13}$ Cf. Artigo 12, §1ㅇ da Lei no 13.089/2015 (BRASIL, 2015) com as alterações da Lei no 13.683 de 19 de junho de 2018 (BRASIL, 2018).
} 
Esta perspectiva projeta como altamente necessários o planejamento administrativo e jurídico, para criação de uma rede interconectada de espaços ambientais que conservam valores e funções ecossistêmicas, provendo benefícios associados às metrópoles e aos aglomerados urbanos que, atualmente, se mostram ambientalmente vulneráveis aos riscos de desastres no Brasil.

Os serviços ecossistêmicos vinculam-se diretamente às ações de prevenção e precaução aos desastres ambientais/climáticos e podem ser evidenciados pelos instrumentos como as Unidades de Conservação, pelas formas de governança interfederativa contidas no Estatuto da Metrópole, pelos dispositivos do Código Florestal, Resoluções do Conselho Nacional do Meio AmbienteCONAMA, Planos de Recursos Hídricos, Planos Diretores de Aptidão Urbanística entre outros. Todos estes instrumentos, ao se integrarem à Política Nacional de Proteção e Defesa Civil, ajustam-se com uma ampliação de função e passam a se constituir como possibilidades de elementos fundamentadores de decisões jurídicas antidesastres.

No que se refere às formas de governança interfederativa o Estatuto da Metrópole apresenta-se como promissor a criação de políticas públicas a partir de serviços ecossistêmicos, por incluir no Plano de Desenvolvimento Urbano Integrado formas de governança dos serviços ecossistêmicos mais abrangentes, privilegiando os critérios geofísicos do território.

$\mathrm{Na}$ construção de novas formas jurídicas ou com diferenciação funcional dos instrumentos já existentes na legislação nacional, um Direito apto a gerir desastres ambientais/climáticos precisa orientar, monitorar e avaliar as decisões seguindo alguns fundamentos e um deles consiste na fixação de competências compartilhadas entre os entre federativos voltados à criação e gestão de políticas de proteção aos desastres.

O estabelecimento de competências em âmbito de governanças interfederativas, recentemente incluído pelo Estatuto da Metrópole - Lei no 13.089/2015, possibilita a parametrização das variáveis e da necessária dinamicidade nas observações locais, regionais, nacionais e até internacionais de serviços ecossistêmicos preventivos e mitigatórios de danos decorrentes de desastres. Tais competências permitem a tomada de decisões conjuntas no redimensionamento do uso do solo, notadamente o urbano, na perspectiva única de construção de resiliência do conjunto das comunidades vulneráveis. Este processo resulta de um Estado de Direito Ambiental que oferece possibilidades de utilização de instrumentos jurídicos voltados à fixação de diretrizes e competências específicas para todos os entes federativos.

\section{REFERÊNCIAS}


ANDRADE, Daniel Caixeta. Valoração econômica ecológica: bases conceituais e metodológicas. São Paulo: Annablume, 2013.

ANGELO, Claudio. Acordo de Paris: a 7,5\% da entrada em vigor. Observatório do Clima. Disponível em: <http://www.observatoriodoclima.eco.br/acordo-de-paris-a-75-da-entrada-em-vigor/>. Acesso em: 02 out.2018.

ANTUNES, Tiago. Os desastres naturais e as alterações climáticas - em especial, a resposta do ordenamento jurídico aos fenômenos meteorológicos extremos. In: Gomes, Carla (coord.). Direito(s) das catástrofes naturais. Coimbra: Almedina, 2012. p. 71-140.

BENSUSAN, Nurit (Org.). Seria melhor mandar ladrilhar? Biodiversidade: como, para que e por quê. 2 ed. São Paulo: Peirópolis, Brasília: Universidade de Brasília, 2008.

BRASIL. Constituição da República Federativa do Brasil de 1988. Disponível em: <http://www.planalto.gov.br/ccivil_03/Constituicao/Constituicao.htm>.

Acesso em: 10 jan. 2018.

Decreto no 2.519, de 16 de março de 1998. Promulga a Convenção sobre Diversidade Biológica, assinada no Rio de Janeiro, em 05 de junho de 1992. Disponível em: <http://www.planalto.gov.br/ccivil_03/decreto/D2519.htm>. Acesso em: 13 jan. 2018.

. Lei no 12.608, de 10 de abril de 2012. Institui a Política Nacional de Proteção e Defesa Civil PNPDEC; dispõe sobre o Sistema Nacional de Proteção e Defesa Civil-SINPDEC e o Conselho Nacional de Proteção e Defesa Civil - CONPDEC; autoriza a criação de sistema de informações e monitoramento de desastres; altera as Leis $\mathrm{n}$ 오 12.340 , de 1 으 de dezembro de 2010, 10.257, de 10 de julho de 2001, 6.766, de 19 de dezembro de 1979, 8.239, de 4 de outubro de 1991, e 9.394, de 20 de dezembro de 1996; e dá outras providências. Disponível em: <http://www.planalto.gov.br/ccivil_03/_Ato2011-2014/2012/Lei/L12608.htm>. Acesso em: 02 jun.2018.

BRASIL. Lei no 13.089, de 12 de janeiro de 2015. Institui o Estatuto da Metrópole, altera a Lei no 10.257, de 10 de julho de 2001, e dá outras providências. Disponível em:

<http://www.planalto.gov.br/ccivil_03/_Ato2015-2018/2015/Lei/L13089.htm>.

Acesso em: 02 out. 2018. 
Lei no. 13.683 de 19 de junho de 2018. Altera as Leis nos 13.089, de 12 de janeiro de 2015 (Estatuto da Metrópole), e 12.587, de 3 de janeiro de 2012, que institui as diretrizes da Política Nacional de Mobilidade Urbana. Disponível em:

http://www.planalto.gov.br/ccivil_03/_Ato2015-2018/2018/Lei/L13683.htm\#art1.

Acesso em: 02 out. 2018.

. Projeto de Lei no 5.487, de 24 de junho de 2009. Institui a Política Nacional dos Serviços Ambientais, o Programa Federal de Pagamento por Serviços Ambientais, estabelece formas de controle e financiamento desse Programa, e dá outras providências. Disponível em: $<$ http://www.camara.gov.br/proposicoesWeb/fichadetramitacao?idProposicao=439941>. Acesso em: 27 jul.2018.

CAPRA, Fritjof. LUISI, Pier Luigi. A Visão sistêmica da vida. Uma concepção unificada e suas implicações filosóficas, políticas, sociais e econômicas. Tradução de Mayara Teruya Eichemberg e Newton Roberval Eichemberg. São Paulo: Cultrix, 2014.

CARVALHO, Délton Winter de. O papel do direito e os instrumentos de governança ambiental para prevenção dos desastres. Revista de Direito Ambiental, ano 19, v. 75, p. 52, jul. /set. 2014.

- Os Planos Diretores de Bacia Hidrográfica e a irradiação de efeitos sobre instrumentos de ordenação territorial. Revista de Direito da Cidade. Rio de Janeiro, v. 8, n. 4, p. 1310-1343, 2016.

CARVALHO, Délton Winter de; DAMACENA, Fernanda Dalla Libera. Direito dos Desastres. Porto Alegre: Livraria do Advogado, 2013.

COSTANZA, Robert. et al. The value of the world's ecosystem services and natural capital. Nature, London, v. 387, n.15, p. 253-260, may 1997.

CHRISTENSEN, Norman L. et al. The report of the Ecological Society of America committee on the scientific basis for ecosystem management. Ecological applications, v. 6, n. 3, p.666, ago. 1996. Disponível em: <http://biology.unm.edu/jhbrown/Documents/Publications/ChristensenEtAl1996EA.pdf.> Acesso em: 13 jan. 2017. 
FARBER, Daniel A. The climate change and Disaster law. In: Seminário do Grupo de Pesquisa (Cnpq) Direito, Risco e Ecocomplexidade. Porto Alegre. O direito ambiental e o direito dos desastres na era das mudanças climáticas. São Leopoldo. Universidade do Vale do Rio dos Sino, 2016.

GUEDES, Fátima Becker; SEEHUSEN, Susan (Org.). Pagamentos por serviços ambientais na Mata Atlântica: lições aprendidas e desafios. Brasília: Ministério do Meio Ambiente, 2011. Disponível em: <http://www.mma.gov.br/estruturas/202/_arquivos/psa_na_mata_atlantica_licoes_aprendidas_e _desafios_202.pdf>. Acesso em: 13 jan. 2018.

HEAL, Geoffrey. Valuing ecosystem services. Ecosystems, New York, EUA, n. 1, v.3, p. 24, jan/.feb, 2000. Disponível em:

<http://www.jstor.org/stable/3658664?seq=1\#fndtn-page_scan_tab_contents>.

Acesso em: 13 jun. 2018.

HOLLING, C. S. et al. Resilience, adaptability, and transformability in social-ecological systems. Ecology and society, v. 9, n. 2, art. 5, 2004. Disponível em: <http://www.ecologyandsociety.org/vol9/iss2/art5/>.Acesso em: 13 jan. 2018. INTERGOVERNMENTAL PANEL ON CLIMATE CHANGE. Global Warming of $1,5^{\circ} \mathrm{C}$. Disponível em: <https://www.ipcc.ch/report/sr15/>. Acesso em: 19 out. 2018.

LEITE, José Rubens Morato. Dano ambiental: do individual ao coletivo extrapatrimonial. 2 ed. São Paulo: Revista dos Tribunais, 2003.

LEITE, José Rubens Morato; BELCHIOR, Germana Neiva. Direito constitucional ambiental brasileiro. In: LEITE, José Rubens Mortato; PERALTA, Carlos E (Org.). Perspectivas e desafios para a proteção da biodiversidade no Brasil e na Costa Rica. São Paulo: Instituto o Direito por uma Planeta Verde, 2014. LUHMANN, Niklas. Sistemas sociales. Lineamientos para una teoría general. Tradução de Silvia Pappe e Brunhilde Erker. México: Anthropos, 1998.

LUHMANN, Niklas. Sociologia do direito I. Tradução de Gustavo Bayer. Rio de Janeiro: Edições Tempo Brasileiro, 1983.

MOURA, Rosa; HOSHINO, Thiago de Azevedo Pinheiro. Estatuto da Metrópole: Enfim aprovado! Mas o que oferece à metropolização brasileira?. Observatório das metrópoles. Disponível em: 
$<$ <ttp://www.observatoriodasmetropoles.net/download/estatuto_metropole_artigo_rosa.pdf>. Acesso em: 14 jan. 2017.

NASA.

Disponível em: https://climate.nasa.gov/images-of-change?id=596\#596-storms-swell-cedar-riveriowa. Acesso em: 30 ago. 2018.

NUSDEO, Ana Maria de Oliveira. Pagamento por serviços ambientais. Sustentabilidade e disciplina jurídica. São Paulo: Atlas, 2012.

MILLENIUM ECOSYSTEM ASSESMENT. Ecosystems and human well-being: synthesis. Washington, DC: Island Press, 2005.Disponível em:

$<$ http://www.millenniumassessment.org/documents/document.356.aspx.pdf>.

Acesso em: 15 jun. 2018.

MOMM. Sandra Irene. As experiências dos municípios de São Paulo no processo de planejamento: metodologia para elaboração da Carta de Aptidão à Urbanização. In: Fórum Permanente de Prevenção aos riscos de desastres na Bacia Hidrográfica do Rio Itajaí, 9. e Seminário do Plano Diretor de Blumenau: Blumenau. Planejamento urbano e regional: construindo cidades resilientes. Blumenau: Universidade Regional de Blumenau, 2016.

MURADIAN, Roldan. et al. Reconciling theory and practice: an alternative conceptual framework for understanding payments for environmental services. Ecological economics, v. 69, n. 6, p. 1202-1208, 2010.

NOBRE, Antônio. As pessoas precisam mudar. [2011]. Entrevistador: Dal Marcondes. 2016. Disponível em: http://www.envolverde.com.br/opiniao/entrevistas2015/antonio-nobre-as-pessoasprecisam-mudar/. Acesso em: 13 jan. 2017. Entrevista concedida ao Jornal Online Envolverde Jornalismo \& Sustentabilidade.

NUSDEO, Ana Maria de Oliveira. Pagamento por serviços ambientais. Sustentabilidade e disciplina jurídica. São Paulo: Atlas, 2012.

PALMER, Margaret. et al. Ecology for a crowded planet. Science, v. 304, n. 5675, p. 1251, may 2004. Disponível em: <http://science.sciencemag.org/content/304/5675/1251.full>. Acesso em: 13 jan. 2017.

PARTNERSHIP FOR ENVIRONMENT AND DISASTER RISK REDUCTION. Post-2015 global tramework on disaster risk reduction. p.3. Disponível em:

<http://pedrr.org/pedrr/wp-content/uploads/2013/11/PEDRR-Key-Messages-Post-2015-DRRFramework_FINAL-with-17-logos.pdf>. 
Acesso em: 13 jan. 2017.

PEREIRA, Reginaldo; WINCKLER, Silvana Terezinha; FRANCO, Gilza Maria da S. Franco. Re-significação dos princípios do direito ambiental a partir da ecologia. Seqüência: estudos jurídicos e políticos, Florianópolis, v. 29, n. 56, p. 144, 2008.

PRIMACK, Richard B.; RODRIGUES, Efraim. Biologia da Conservação. Londrina: E. Rodrigues, 2001.

ROMEIRO, Ademar Ribeiro. Desenvolvimento sustentável: uma perspectiva econômicoecológica. Estudos avançados, São Paulo, v. 26, n. 74, p. 65-92, 2012. Disponível em:

<http://periodicos.usp.br/eav/article/view/10625/12367>. Acesso em: 13 jan. 2018.

RUHL, J. B.; KRAFT Steven E.; LANT, Christopher. The law and policy of ecosystem services. Washington: Island Presss, 2007.

SCHERER, Kátia Ragnini. A função do Direito na gestão do risco climático. Rio de Janeiro, 2017: Lumen Juris, 2017.

TRAVASSOS, Luciana. Rios Urbanos, entre políticas de drenagem e sua integração à paisagem. In: SCHULT, Sandra Irene Momm; BOHN, Noemia (Org.) As múltiplas dimensões das Áreas de Preservação Permanente. Blumenau: Edifurb, 2014.

TEUBNER, Gunther. Direito, sistema e policontexturalidade. Piracicaba: Unimep, 2005.

TOWNSEND, Colin R; BEGON, Michel; HARPER, John L. Tradução de Leandro da Silva Duarte. Fundamentos em ecologia. 3 ed. Porto Alegre: Artmed, 2010.

UNITED NATIONS ENVIRONMENT PROGRAMME. Ecosystems and their services. p. 49. Disponível em: <http://www.unep.org/maweb/documents/document.300.aspx.pdf>. Acesso em: 13 jan. 2017. VERCHICK, Robert R. Facing catastrophe. Environmental action for a post-Katrina world. Cambridge, Massachusetts: Harvard University Press, 2010.

WAYCARBON. Ver para crer? NASA apresenta imagens das mudanças climáticas. Disponível em: $<$ https://blog.waycarbon.com/2017/01/nasa-mudancas-climaticas-imagens/>.Acesso em: 30 ago.2018.

Trabalho enviado em 19 de outubro de 2018

Aceito em 20 de fevereiro de 2019 